KEY MESSAGES FROM
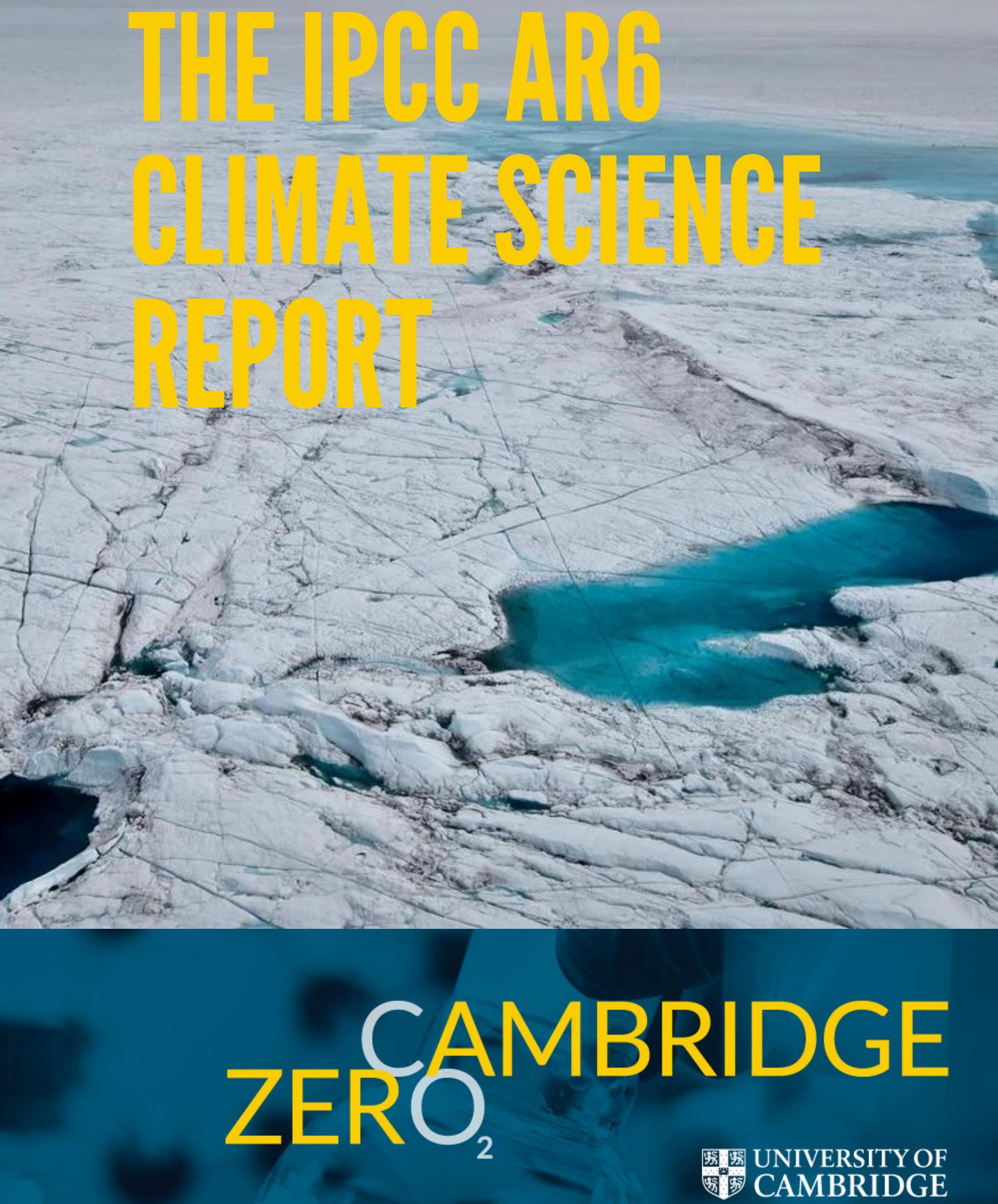


\section{KEY MESSAGES FROM THE IPCC ARG CLIMATE SCIENCE REPORT}

\section{Alison Ming, Isobel Rowell, Sam Lewin, Robert Rouse, Thomas Aubry, Emma Boland Cambridge Centre for Climate Science}

The United Nations' Intergovernmental Panel on Climate Change (IPCC) has published the first part of its sixth assessment report (AR6) which summarises the latest climate science findings and will guide policy in the years ahead. This report is particularly timely, as world leaders prepare to respond to the climate crisis at the UN COP26 climate summit in Glasgow this November. The full AR6 report is an enormous scientific undertaking that assesses the physical science basis for climate change and assembles the findings from over 14,000 peer reviewed publications. The purpose of this briefing document is to provide a succinct summary of the key scientific messages which are:1

- Human influence has caused climate change and is leading to more frequent extreme events such as heatwaves, heavy precipitation, and droughts, and to continuing sea level rise.

- We now have better estimates of how sensitive the climate system is to carbon dioxide, and so can better predict the result of further emissions or reductions.

- Even under the most aggressive emissions reductions scenario, the world will continue to warm until at least 2050.

- Carbon dioxide in the atmosphere is additive. Every ton of carbon dioxide warms the planet.

- There is still time to avoid dangerous climate change, and the effects of reducing emissions would be felt within decades.

\section{A. Current state of the climate}

It is unequivocal that human influence has warmed the atmosphere, ocean and land, with each of the last four decades being successively warmer than any decade that preceded it since 1980. A proportion of the radiation arriving from the Sun is trapped in Earth's atmosphere. Increased greenhouse gas concentrations trap additional radiation, causing a build up of energy in the Earth system and leading to warming. Specifically, to list some of the important observed changes, global surface temperatures in the past decade were $1^{\circ} \mathrm{C}$ higher than those of the pre-industrial period, the September Arctic sea ice area has decreased by $40 \%$ in 2010-2019 compared to 1979-1988, the global mean sea level has risen by $0.2 \mathrm{~m}$ between 1901-2018 and the growing season in the Northern Hemisphere extratropics has been extended by two days per decade since the 1950s. The rate of warming is unprecedented in at least the last 2000 years as shown in Figure 1(a). Climate model simulations (green) with only natural drivers, Figure 1(b), are not able to capture the observed changes (orange) and we can clearly see the emergence of an anthropogenic climate change signal in the global surface temperature above the natural and internal variability from the year 2000 onwards. 
a) Change in global surface temperature (decadal average) as reconstructed (1-2000) and observed (1850-2020)

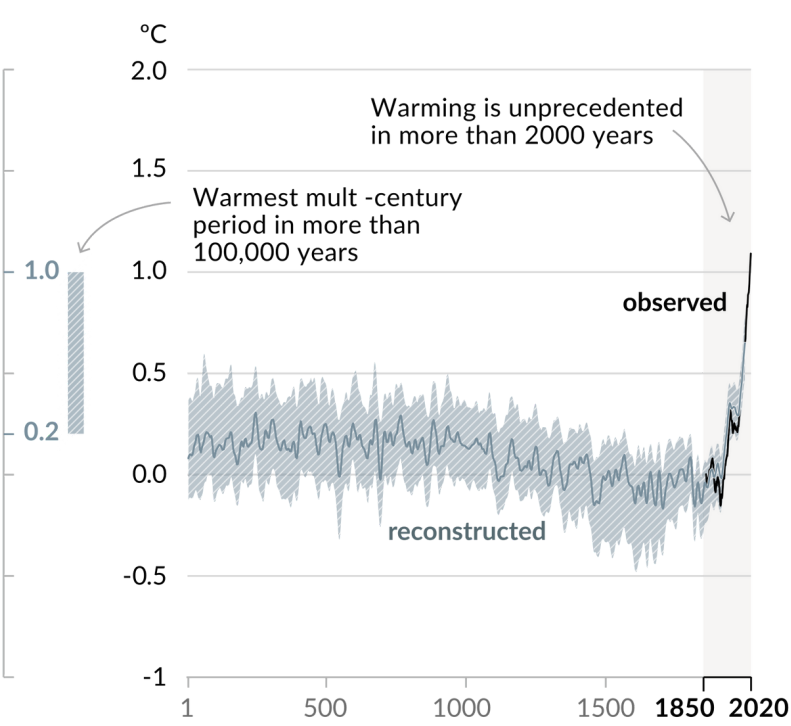

b) Change in global surface temperature (annual average) as observed and simulated using human \& natural and only natural factors (both 1850-2020)
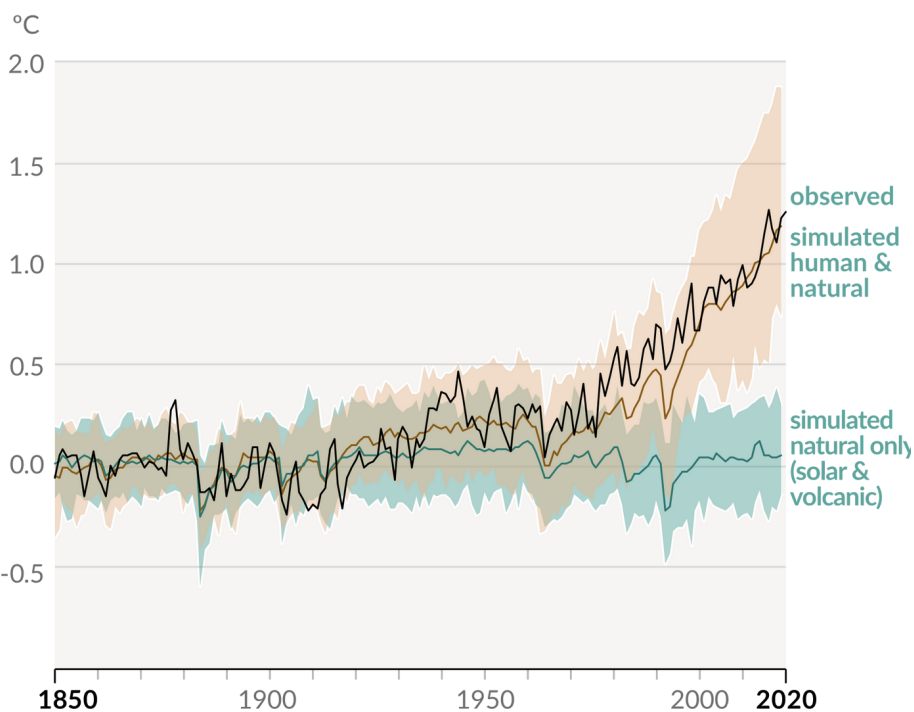

Figure 1: [Adapted from Figure SPM.1] History of global temperature change and causes of recent warming.

The impacts of climate change are already being felt globally in a very real way through extreme weather events. Heatwaves and extreme precipitation events are becoming more frequent and severe, while cold events are less common and intense. Since the previous IPCC report (AR5), we can say with even more confidence that human activity is responsible for these changes. Recent hot extremes, which have been experienced in nearly all regions globally, were extremely unlikely to have occurred without human influence, Figure 2.
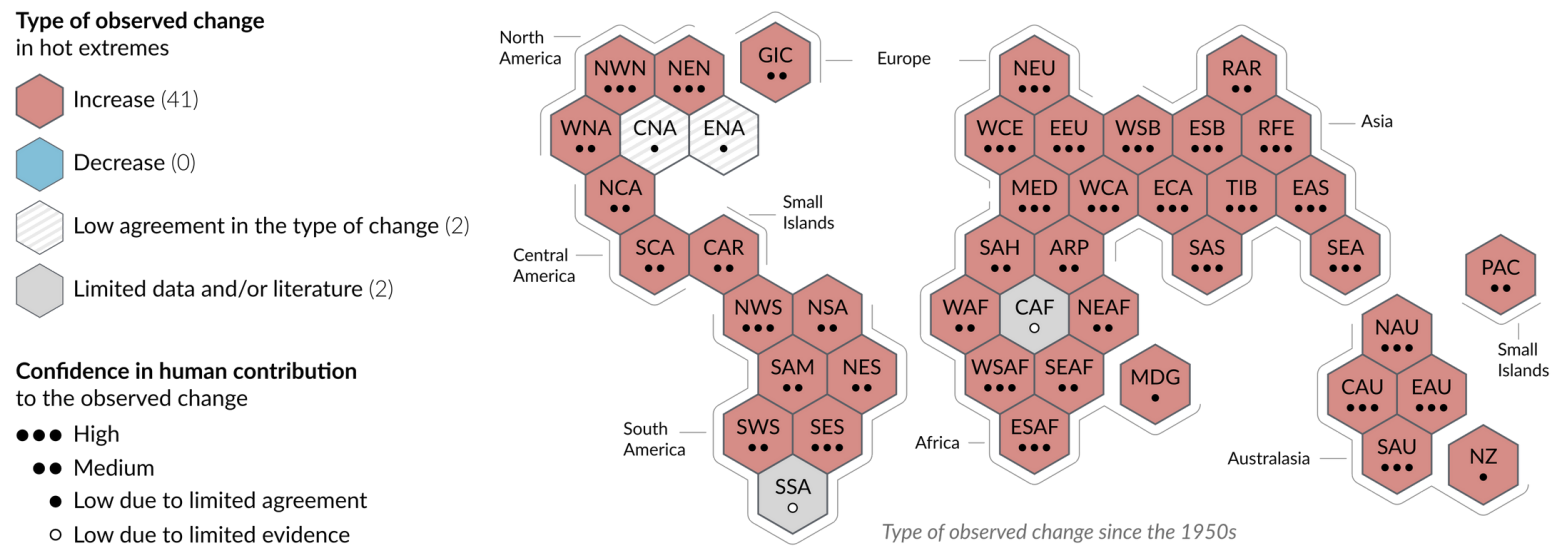

Figure 2: [Adapted from Figure SPM.3] Synthesis of assessment of observed change in hot extremes and confidence in human contribution to the observed changes in the world's regions. Each hexagon corresponds to one of the IPCC AR6 reference regions.

Human impacts on global monsoon precipitation are more complex, but increases since the 1980 s are attributable to rising GHG concentrations. Compound extreme events, such as concurrent heatwaves and droughts, fire and compound flooding, have likely been increased by human activity. 
The rising temperature is also causing ice melt and thermal expansion of the oceans, leading to higher sea levels. AR6 has shown that while thermal expansion of the oceans was the major cause of sea level rise from 1971 to 2018, the acceleration of ice sheet loss means ice melt is now the dominant contributor.

AR6 has compiled more accurate estimates of equilibrium climate sensitivity - the change in temperature resulting from a doubling of $\mathrm{CO}_{2}$ in the atmosphere compared to the preindustrial period-which have settled on $+3^{\circ} \mathrm{C}$, with a narrower range compared to previous estimates. This means we can understand more accurately how much warming to expect from different emissions scenarios.

\section{B. Possible climate futures}

In order to explore the climate response to changing levels of atmospheric pollutants, the IPCC report outlines five illustrative future emissions scenarios for the $21^{\text {st }}$ century, termed Shared Socio-economic Pathways (SSPS). These SSPs are designed to cover a range of developments in human-caused $\mathrm{CO}_{2}$ and non- $\mathrm{CO}_{2}$ emissions, taking into account potential socio-economic developments and different levels of climate change mitigation. The lowest two emission scenarios rely on negative emissions after 2055 to reach their long term outcomes. We have summarised the scenarios and associated projections in Table 1.

\begin{tabular}{|c|c|c|c|c|}
\hline \multirow[b]{2}{*}{ Scenario } & \multirow[b]{2}{*}{ Description } & \multicolumn{3}{|c|}{ Predictions } \\
\hline & & $\begin{array}{l}\text { Short term } \\
(2021-2040)\end{array}$ & $\begin{array}{r}\text { Medium term } \\
(2041-2060)\end{array}$ & $\begin{array}{l}\text { Long term } \\
(2081-2100)\end{array}$ \\
\hline SSP1-1.9 & $\begin{array}{c}\text { Very low emissions } \\
\text { and decreasing to } \\
\text { net zero by } 2055\end{array}$ & 1.2 to $1.7^{\circ} \mathrm{C}$ & 1.2 to $2.0^{\circ} \mathrm{C}$ & 1.0 to $1.8^{\circ} \mathrm{C}$ \\
\hline SSP1-2.6 & $\begin{array}{l}\text { Low emissions } \\
\text { and decreasing to } \\
\text { net zero by } 2080\end{array}$ & 1.2 to $1.8^{\circ} \mathrm{C}$ & 1.3 to $2.2^{\circ} \mathrm{C}$ & 1.3 to $2.4{ }^{\circ} \mathrm{C}$ \\
\hline SSP2-4.5 & Intermediate emissions & 1.2 to $1.8^{\circ} \mathrm{C}$ & 1.6 to $2.5^{\circ} \mathrm{C}$ & 2.1 to $3.5{ }^{\circ} \mathrm{C}$ \\
\hline SSP3-7.0 & High emissions & 1.2 to $1.8{ }^{\circ} \mathrm{C}$ & 1.7 to $2.6{ }^{\circ} \mathrm{C}$ & 2.8 to $4.6{ }^{\circ} \mathrm{C}$ \\
\hline SSP5-8.5 & Very high emissions & 1.3 to $1.9^{\circ} \mathrm{C}$ & 1.9 to $3.0^{\circ} \mathrm{C}$ & 3.3 to $5.7^{\circ} \mathrm{C}$ \\
\hline
\end{tabular}

Table 1: [Adapted from Table SPM.1] Changes in global surface temperature, relative to the average global surface temperature of the period 1850-1900, under different emissions scenarios 
Predictions of future temperatures from each scenario are obtained from a large group of climate models. These models are more accurate and have a higher resolution than those used in previous IPCC reports. All scenarios are likely to reach $1.5^{\circ} \mathrm{C}$ of global warming by 2050 . Without a significant decrease in GHG emissions, global surface temperatures are projected to increase by a minimum of $2.1^{\circ} \mathrm{C}$ by 2100 compared to $1850-1900$. The last time temperatures were sustained at more than $2.5^{\circ} \mathrm{C}$ above those of 1850-1900 was over 3 million years ago. However, in the lowest emissions scenario (SSP1-1.9), which becomes carbon negative by 2055 , temperatures begin to decrease again by the end of the century.

To assess the environmental impact of a given amount of global warming (e.g. $2^{\circ} \mathrm{C}$ ), the report looked at an average of all models from the scenarios that reached this amount of warming. All warming scenarios indicate that land surface temperatures will rise more than sea surface temperatures. In the Arctic, temperatures are projected to rise more than twice as fast as the global warming rate, resulting in it being practically free of sea-ice, at least once by 2050 , in all future scenarios. The frequency of hot temperature extremes, droughts, heavy precipitation events and tropical cyclones all increase with each additional $1^{\circ} \mathrm{C}$ of global warming.

Under all scenarios, the world will become wetter and the global increase in precipitation could be up to $13 \%$ before 2100 compared to 1994-2010; however, the effects of this increase will not be felt uniformly, with some areas of the world experiencing less rainfall, such as parts of the subtropics. Rising temperature will also result in more frequent and more intense wet and dry weather events. A warmer atmosphere can hold more water vapour, while in arid areas, droughts become more common because of the increased evaporation of soil moisture. This will drive more impactful flooding and droughts, with the one-in-ten-year heavy rainfall event being 2.7 times more likely and 30\% more intense under the highest emissions scenarios.

The loss of mountain and polar glaciers, and permafrost 3 is likely to continue, and the Greenland Ice Sheet will continue to melt over the $21^{\text {st }}$ century. Combined with ocean warming, in particular deep ocean warming, sea level rise is unavoidable. Even in the lowest emissions scenario SSP1-1.9, mean sea level is predicted to increase by 0.28 to $0.55 \mathrm{~m}$ by 2100 . The highest emissions scenario SSP5-8.5 predicts an increase of 0.63 to $1.01 \mathrm{~m}$ and has the potential to reach $2 \mathrm{~m}$ as early as 2150 . These changes are locked in to a certain extent, with the effects of warming continuing to drive a response for hundreds if not thousands of years. On the same timescales, the oceans will also undergo other changes, including acidification and deoxygenation, which could have far reaching and devastating consequences for marine ecosystems.

As the land and oceans are affected by warming, their ability to reduce the effects of said warming is diminished. Carbon sinks 4 will become less effective and feedback mechanisms between climate change and the carbon cycle, whereby changes in one affects the other, will become more impactful and severe under higher emissions scenarios. For example, the melting of permafrost releases methane, a greenhouse gas that causes more warming that, in turn, results in further loss of permafrost. 


\section{Climate Information for Risk Assessment and Regional Adaptation}

Risk assessments should take into account the fact that human-caused climate change is also modified by natural variability in different regions of the globe. However, these factors have little effect on global warming in the long term. Furthermore, for every additional degree of global warming, every region is projected to see increasing changes in weather including mean temperature and precipitation, extreme heat days, or floods from extreme rainfall. Regardless of the level of global warming, we cannot rule out climate change outcomes that are deemed unlikely but would have high impacts on regional and global climate. These include forest dieback, ice-sheet collapse or abrupt changes in ocean circulation.

Table 2 highlights projected changes for the Northern Europe region which includes the UK. Under the current state of emissions, changes in climate due to global warming over the coming decades are now unavoidable. However, the future emissions pathway we choose to follow will have a key impact on climate projections by the end of the century and in the longer-term. Should we follow a high emission scenario (SSP3-7.0), the Northern Europe region could see temperatures increase by 3.1 to $7^{\circ} \mathrm{C}$ and precipitation increase by 2.8 to $23.4 \%$ by the end of the century. For a complete perspective of observed and projected climate change in the UK, we refer the reader to the report by Slingo (2021) 5 .

\begin{tabular}{|c|c|c|c|c|}
\hline Scenario & \multicolumn{2}{|c|}{ SSP1-2.6 } & \multicolumn{2}{|c|}{ SSP3-7.0 } \\
\hline Period & $2021-2040$ & $2081-2100$ & $2021-2040$ & $2081-2100$ \\
\hline $\begin{array}{l}\text { Mean temperature } \\
\left({ }^{\circ} \mathrm{C}\right)\end{array}$ & $\begin{array}{c}\mathbf{2 . 2} \\
{[0.9 \text { to } 4.2]}\end{array}$ & $\begin{array}{c}\mathbf{2 . 7} \\
{[0.9 \text { to } 4.2]}\end{array}$ & $\begin{array}{c}\mathbf{2 . 2} \\
{[1.0 \text { to } 3.5]}\end{array}$ & $\begin{array}{c}\mathbf{4 . 9} \\
{[3.1 \text { to } 7.0]}\end{array}$ \\
\hline $\begin{array}{l}\text { Yearly number of } \\
\text { frost days (day) }\end{array}$ & $\begin{array}{c}\mathbf{- 3 2 . 6} \\
{[-59.0 \text { to }-11.5]}\end{array}$ & $\begin{array}{c}\mathbf{- 4 1 . 7} \\
{[-70.9 \text { to }-18.8]}\end{array}$ & $\begin{array}{c}\mathbf{- 3 1 . 1} \\
{[-51.4 \text { to }-9.8]}\end{array}$ & $\begin{array}{c}\mathbf{- 6 6 . 6} \\
{[-85.4 \text { to }-49.2]}\end{array}$ \\
\hline $\begin{array}{l}\text { Total Precipitation } \\
\text { ( } \% \text { change) }\end{array}$ & $\begin{array}{c}\mathbf{5 . 3} \\
{[1.9 \text { to } 8.9]}\end{array}$ & $\begin{array}{c}\mathbf{6 . 4} \\
{[0.3 \text { to } 14.0]}\end{array}$ & $\begin{array}{c}\mathbf{5 . 5} \\
{[0.4 \text { to } 9.7]}\end{array}$ & $\begin{array}{c}11.5 \\
{[2.8 \text { to } 23.4]}\end{array}$ \\
\hline $\begin{array}{l}\text { Maximum 5-day } \\
\text { precipitation } \\
\text { ( } \% \text { change) }\end{array}$ & $\begin{array}{c}\mathbf{7 . 6} \\
{[3.8 \text { to } 12.7]}\end{array}$ & $\begin{array}{c}\mathbf{8 . 9} \\
{[2.4 \text { to } 16.8]}\end{array}$ & $\begin{array}{c}\mathbf{7 . 3} \\
{[3.7 \text { to } 11.8]}\end{array}$ & $\begin{array}{c}\mathbf{1 7 . 0} \\
{[10.0 \text { to } 30.6]}\end{array}$ \\
\hline Snowfall (mm/day) & $\begin{array}{c}-\mathbf{4 . 2} \\
{[-7.5 \text { to }-1.3]}\end{array}$ & $\begin{array}{c}\mathbf{- 5 . 5} \\
{[-8.7 \text { to }-2.0]}\end{array}$ & $\begin{array}{c}\mathbf{- 4 . 2} \\
{[-7.1 \text { to }-1.4]}\end{array}$ & $\begin{array}{c}-\mathbf{9 . 2} \\
{[-13.4 \text { to }-5.3]}\end{array}$ \\
\hline
\end{tabular}

Table 2: Projected regional changes, relative to 1850-1900, for the Northern Europe Region (which includes the UK). Changes are shown for 5 climate metrics, in the near term (2021-2040) and long term (2081-2100) time horizons, and for the low (SSP1-2.6) and high (SSP3-7.0) emission scenarios. Changes shown are median projections with numbers in parenthesis indicating the $90 \%$ confidence interval. All numbers are from the IPCC WGI Interactive Atlas 


\section{Limiting future climate change}

Given what the report says about the likely effects of on-going climate change, what can be done to slow or even reverse human-induced warming?

Every extra tonne of carbon dioxide added to the atmosphere contributes to global warming, regardless of which possible future is chosen, as can be seen from Figure 3. This means that if we want to halt global warming at a certain level, we must limit the total amount of carbon dioxide in the atmosphere.

The Paris Agreement sets an aspiration to limit warming to $1.5^{\circ} \mathrm{C}$ above pre-industrial levels in order to avoid 'dangerous' climate change. The AR6 report estimates that, to have a 50:50 chance of meeting this target, we can emit approximately 500 more gigatonnes of carbon dioxide into the atmosphere. We have already emitted around 2,400 gigatonnes. Reducing other pollutants such as methane could buy more time, as well as quickly improving air quality.

The good news is that, for the first time, AR6 shows that low-emissions scenarios combined with carbon capture and storage would rapidly limit the effects of climate change and we would see impacts on global temperature within 20 years.

Global surface temperature increase since $1850-1900\left({ }^{\circ} \mathrm{C}\right)$ as a function of cumulative $\mathrm{CO}_{2}$ emissions $\left(\mathrm{GtCO}_{2}\right)$

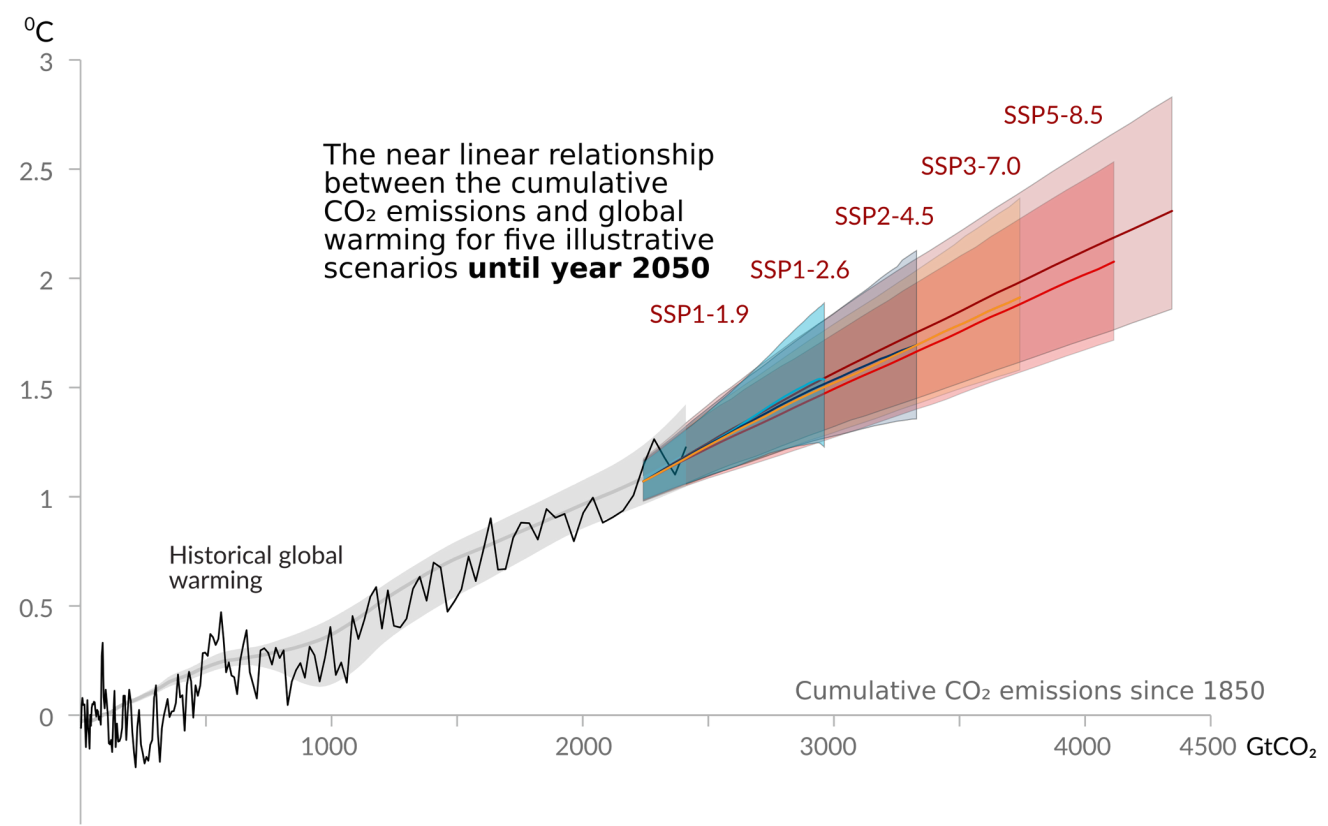

Figure 3: [Adapted from Figure SPM.10] Near-linear relationship between cumulative CO2 emissions and the increase in g/obal surface temperature. The grey range with its central line shows a corresponding estimate of the historical human-caused surface warming. Coloured areas show the assessed very likely range of global surface temperature projections, and thick coloured central lines show the median estimates as a function of cumulative CO2 emissions from 2020 until 2050 for the set of illustrative SSPS. 
1. Values quoted in this document represent best estimates taken from the IPCC AR6 report.

2. Figures are adapted from the Summary for Policymakers where more detailed captions can be found.

3. Permafrost is any ground that remains completely frozen for at least two years in a row.

4. A reservoir (natural or human, in soil, ocean, and plants) where carbon is stored.

5. UK Climate Risk Independent Assessment (CCRA3) Technical Report, Chapter 1.

Front cover photo credit: Ian Joughin (distributed via imaggeo.egu.eu) 


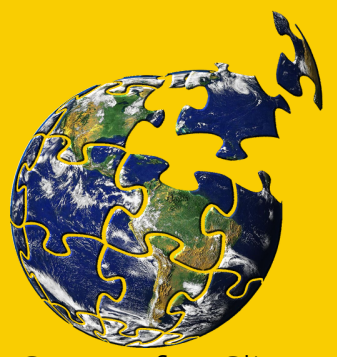

Cambridge Centre for Climate Science

$$
\underbrace{\begin{array}{l}
\text { Isaac } \\
\text { Newton } \\
\text { Trust }
\end{array}}_{\text {Supported by }}
$$

\section{CAMBRIDGE

